\title{
European Alliance Against Depression - et fireplans intervensjonsprogram mot depresjon og suicidalitet
}

Ved Ulrich Hegerl ${ }^{1}$, Anna Cibis² ${ }^{2}$ Ella Arensman³ ${ }^{3}$, Esa Aromaa ${ }^{4}$, Chantal van Audenhove ${ }^{5}$, Jean-Hervé Bouleau ${ }^{6}$, Christina M van der Feltz-Cornelis 7, Giancarlo Giupponi ${ }^{8}$, Ricardo Gusmäo9 ${ }^{9}$ Maria Kopp ${ }^{10}$, Andrej Marusic ${ }^{11}$, Margaret Maxwell ${ }^{12}$, Ullrich Meise ${ }^{13}$ Högni Oskarsson ${ }^{14}$, Charles Pull15, Regula Ricka ${ }^{16}$, Armin Schmidtke17, Victor Pérez Sola ${ }^{18}$, Merike Sisask19 \& Lisa Wittenburg20

I European Alliance Against Depression (EAAD) samarbeider partnere fra 17 europeiske land med mål om å bedre omsorgen for deprimerte pasienter og forebygge suicidalitet. Lokalt baserte intervensjoner blir iverksatt i forskjellige regioner og omfatter aktiviteter på følgende fire plan: 1) samarbeid med allmennpraktiserende leger, 2) informasjonskampanjer rettet mot allmennheten, 3) bruk av lokale nøkkelpersoner og 4) initiativer rettet mot høyrisikogrupper og selvhjelpstiltak. Nürnberg-alliansen mot depresjon har skaffet vitenskapelig belegg for effekten av dette intervensjonsprogrammet ved å påvise en betydelig reduksjon i antall suicidalhandlinger $\mathrm{i}$ intervensjonsregionen, sammenlignet med en kontrollregion. Erfaringene fra 17 europeiske land viser at dette intervensjonsprogrammet på fire nivåer og det materialet som anvendes, lett kan tilpasses forskjellige land og ulike kulturelle sammenhenger. Ifølge det såkalte Green Paper fra Europakommisjonen er EAAD et eksempel på "best practice" for et internasjonalt samfunnsbasert opplegg til forebygging av suicidalitet.

\section{Innledning}

I betraktning av at selvmord i de fleste land er en av de ti hyppigste dødsårsakene, blir virkningene av selvmord ofte undervurdert (Bertolote et al., 2005). Iføl ge data fra Verdens helseorganisasjon representerte selvmord $2,4 \%$ av den globale sykdomsbyrden i 2020, sammenlignet med 1,8 \% i 1998 ( Verdens helseorganisasjon, 2003). D et antas at psykiatriske lidel ser utgjør en av de vanligste årsakene til selvmord. Psykologiske autopsistudier har vist at rundt $90 \%$ av alle selvmord blir utført i forbindelse med psykiske lidelser (Lönnqvist et al., 1988; M ann et al., 2005). Den lidelsen som oftest blir påvist, er alvorlig depresjon, selv om schizofreni og stoffrelaterte lidelser også opptrer ganske hyppig (Bertolote et al., 2003; Brent et al., 1994). Følgelig vil en viktig strategi for å forebygge selvmord bestå i å forbedre omsorgen for deprimerte pasienter. I tillegg anbefal er ( $M$ ann et al., 2005) intervensjoner på flere plan som en vellykket tilnærming til forebygging, etter nylig å ha gjort en gjennomgang av effektive sel vmordsforebyggende strategier.

European A lliance A gainst Depression (EA A D) ble opprettet i 2004 med det formål å iverksette lokalt baserte fireplans intervensjoner rettet mot depresjon og suicidalitet (www.eaad.net). Partnere fra 17 land samarbeider om dette prosjektet, som finansieres av Europakommisjonen. Belegg for hvor effektivt intervensjonsprogrammet er, har man skaffet seg gjennom et pilotprosjekt i regi av N ürnbergalliansen mot depresjon ( $\mathrm{H}$ egerl et al., 2007). Ved å samarbeide om dette konseptet forbedrer EA A D-partnerne sine egne regionale erfaringer, og utveks lingen resulterer i stadige forbedringer. Denne vellykte implementeringen ble av Europakommisjonen fremhevet som et "eksempel på beste praksis" i et såkalt $\mathrm{G}$ reen Paper med tittelen "Improving the mental health of the population: Towards a strategy on mental health for the European U nion (Europakommisjonen, 2005).

\section{Erfaringene fra Nürnberg- alliansen mot depresjon}

N ürnberg-alliansen mot depresjon ble gjennomført som et underprosjekt av "G erman Research $\mathrm{N}$ etwork on Depression and Suicidality" (opprettet av den tyske forbundsregjeringens departement for utdanning og forskning) og hadde utviklet et konsept med tilhørende materiell for et lokalt basert intervensjonsprogram rettet mot depresjon og suicidalitet ( $\mathrm{H}$ egerl et al., 2006). Prosjektet kom i gang i 2000 som var basisåret, og der man inkluderte en intervensjonsregion ( $\mathrm{N}$ ürnberg, 500000 innbyggere) og en kontrollregion (W ürzburg, 270000 inn byggere).

I 2001 og 2002 ble et fireplans intervensjonsprogram gjennomført i N ürnberg (fig. 1 neste side). M ålet var å optimalisere omsorgen for deprimerte pasienter og på den måten redusere suicidaliteten.

Følgende fire plan (figur 1) ble valgt:

\section{Første plan: Samarbeid med allmenn- praktiserende leger}

Det store flertallet av deprimerte pasienter kommer først i kontakt med fastlegen sin. 0 gså når det gjelder suicidalitet har man funnet at om lag $77 \%$ av alle personer som døde av selvmord, hadde kontakt med personell innenfor primærhel setjenesten det siste året før de døde (Luoma m.fl., 2002). Disse resultatene understreker den rollen allmennpraktiserende leger spiller $\mathrm{i}$ forbindelse med selvmordsforebyggende tiltak.

Intervensjonen som ble gjennomført ved hjelp av leger i primærhelsetjenesten, omfattet interaktiv opplæring med sikte på å forbedre diagnostiske og terapeutiske ferdigheter i forhold til depresjon, samt håndtering av akutt suicidalitet. U nder denne opplæringen delte man ut og anbefalte den vel prøvde skalaen W H O-5 som screeningverktøy for å identifisere deprimerte pasienter ( $H$ enkel et al., 2003). Blant den store mengden tilleggsmateriale som allmen npraktikerne mottok, var en video som legene kunne gi til deprimerte pasienter. Pasientene fikk anledning til å ta med seg videoen hjem slik at de kunne få mer kunnskap om depresjonssykdom.

\footnotetext{
${ }^{1}$ D epartment of Psychiatry, U niversitetet i Leipzig, Tyskland ${ }^{2}$ D epartment of Psychiatry, U niversitetet i Leipzig, Tyskland ${ }^{3} \mathrm{~N}$ ational Suicide Research Foundation, Cork, Den irske republikk 4 Vaasa H ospital District, Psychiatric U nit, Vaasa, Finland 5 LU CA S - Katholieke U niversiteit Leuven, Belgia ${ }^{6}$ Fédération de Psychiatrie, Hôpital René Dubos, Pontoise, Frankrike 7 Trimbos instituut, U trecht og VU medical Centre Institute of extramural research, A msterdam, N ederland ${ }^{8} \mathrm{~A}$ utonome Provinz Südtirol, A ssessorat für das $\mathrm{G}$ esundheitswesen, Bozen, Italia 9 U niversidade $\mathrm{N}$ ova de Lisboa, Faculdade de Ciências M édicas, Lisboa, Portugal ${ }^{10}$ Semmelweis U niversity Budapest, U ngarn ${ }^{11}$ Institute of Public H ealth of the Republic of Slovenia, Ljubljana, Slovenia 12 D epartment of A pplied Social Science, U niversity of Stirling, Skottland, Storbritannia 13 G esellschaft für Psychische G esundheit - pro mente tirol, Innsbruck, $\emptyset$ sterrike ${ }^{14}$ Directorate of $\mathrm{H}$ ealth C ampaign A gainst Depression and Suicide, Seltjarnarnes, Island ${ }^{15} \mathrm{C}$ entre H ospitalier de Luxembourg, Luxemburg ${ }^{16}$ Bundesamt für G esundheit, Bern, Sveits ${ }^{17}$ Clinic for Psychiatry and Psychotherapy, U niversity of W ürzburg, Tyskland ${ }^{18} \mathrm{H}$ ospital de la Santa C reu i Sant Pau Psychiatry Department, Barcelona, Spania 19 Estonian-Swedish M ental $\mathrm{H}$ ealth and Suicidology Institute; Estonian Centre of Behavioural and $\mathrm{H}$ ealth Sciences, Tallinn, Estland ${ }^{20}$ Department of Psychiatry, U niversitetet i Leipzig, Tyskland
} 


\section{-}

Figur 1. Nürnberg-alliansen mot depresjon: intervensjoner på fire plan

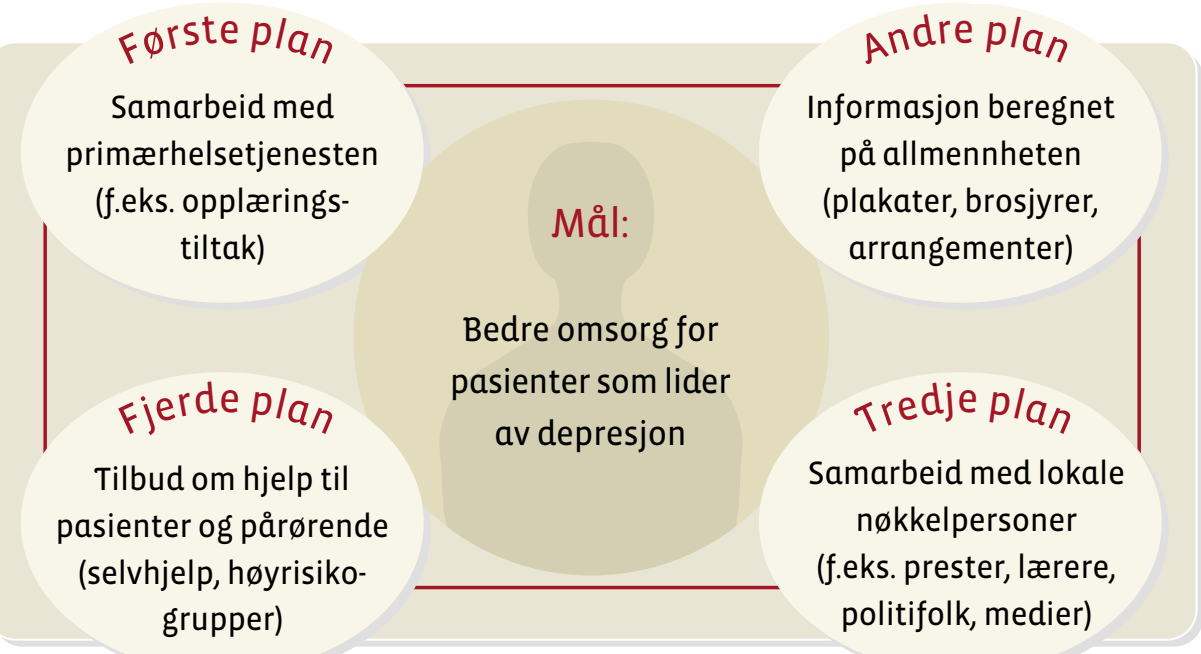

\section{A ndre plan: Informasjonskampanje}

Foruten å bedre tilbudet i primærhelse -tjenesten var et annet viktig mål å bekjempe stigmatiseringen personer med psykiske lidel ser ofte er utsatt for. N ürnberg-alliansen mot depresjon gjennomførte derfor en profesjonell informasjonskampanje rettet mot det store publikum. $M$ ålet med kampanjen var å få bukt med feiloppfatninger og utilstrekkelige kunnskaper om depresjon og suicidalitet og på den måten styrke deprimerte pasienters muligheter til å få profesjonell bistand. M ediekampanjen formidlet tre sentrale budskap: "D epresjon lar seg behandle", "Depresjon har mange ansikter" og "Depresjon kan ramme alle". Videre omfattet informasjonskampanjen utdeling av diverse informasjonsmateriell (foldere, brosjyrer, videoer), samt at det ble avholdt opplysningsarran gementer. U like plakater som rommet de sentrale budskapene, ble rettet mot forskjellige mål grupper ved at de hadde særskilte visuelle motiver, som for eksempel en gammel mann og et ungt par (figur 2).

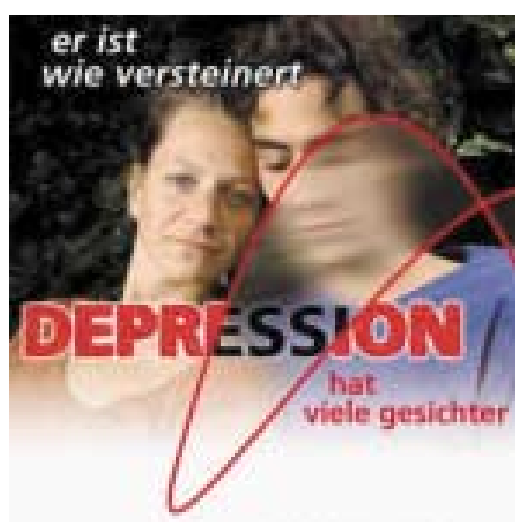

Figur 2: Plakat brukt i informasjonskampanjen til Nürnbergalliansen mot depresjon: Depresjon har mange ansikter.
I tillegg ble det innledet et tett samarbeid mellom de lokale koordinatorene og massemedia i intervensjonsområdet. For å unngå risiko for smitteeffekter utarbeidet man retningslinjer for hvordan journalister kan dekke selvmord på en ansvarlig måte i mediene. U nder henvisning til den såkalte "W erther-effekten" (W asserman, 1984) kom man med anbefalinger om hvordan selvmord bør omtales, f.eks. ved å unngå sen sasjonspregete oppslag, unngå å skrive detaljert omkring selvmordshandlinger, ikke nevne motiver for selvmordshandlinger og personlige detaljer m.v.

\section{Tredje plan: Lokale nøkkelpersoner}

I likhet med allmennpraktiserende leger har lokale nøkkel personer som har regelmessig kontakt med høyrisikogrupper, stor innvirkning på hvilken behandling disse personene skal få. $M$ an gjennomførte derfor opplæringstiltak for sosial arbeidere, prester, geriatriske sykepleiere, lærere, fengselsansatte, farmasøyter, politifolk og andre for å styrke deres kunnskaper om depresjon og suicidalitet. Disse opplæringstiltakene ble tilpasset de behovene og oppgaver den enkelte lokale nøkkelperson hadde. Foruten opplæringen var et annet mål med intervensjonene på dette planet å bygge ut nettverket mellom nøkkel personene (og dessuten allmennpraktikerne).

\section{Fjerde plan: høyrisikogrupper og selvhjelpsgrupper}

D eprimerte pasienter og personer som tidligere har gjort selvmordsforsøk, utgjør særskilte risikogrupper for selvmord. Det å dele ut kort med informasjon til bruk i kriser til alle som hadde gjort forsøk på å ta sitt eget liv, var ett av tiltakene på dette planet. På kortet stod det oppgitt et telefonnummer man kunne ringe for å få profesjonell bistand. A ndre tiltak var å støtte selvhjelpsinitiativer og å opprette nye sel vhjel psgrupper.

\section{Evaluering av Nürnberg- alliansen mot depresjon}

A priori hadde man definert antall selvmordshandlinger som utfall smål, og man kombinerte antall selvmord og ikke-dødelige selvmordshandlinger. Dette utfallsmålet ble valgt, for selv $\mathrm{i}$ en by som $\mathrm{N}$ ürnberg (med 500000 innbyggere) er den basisraten for selvmord for lav og de tilfeldige årlige svingningene for høye til å kunne påvise selv en klar nedgang $i$ antall selvmord statistisk.

A ntallet selvmordshandlinger i N ürnberg sank med $24 \%$ fra basisåret (2000) $i$ løpet av de to intervensjonsårene (2001-2002). En ytterligere nedgang på $32 \%$ ble observert i oppfølgingsåret (se figur 3 neste side). Disse resultatene representerer en statistisk signifikant og klinisk høyst relevant reduksjon i antall selvmordshandlinger i N ürnberg sammenlignet med kontrollregionen, der raten holdt seg stabil (H egerl et al., 2006). $\mathrm{N}$ edgangen var enda mer uttalt ( $53 \%$ ) når man bare tok for seg de fem mest drastiske metodene for selvmordsforsøk.

Etter å ha vakt stor interesse har det opprinnelige prosjektet spredt seg til hele Tyskland, med det resultat at 40 regioner faktisk gjennomfører sine egne fireplansopplegg under paraplyen "D en tyske allianse mot depresjon".

\section{Ytterligere forbedring og eva-} luering av et fireplans intervensjonsprogram innenfor EAAD

Intervensjonene i de europeiske regionene som deltar, er utviklet langs de samme linjene som i pilotprosjektet $i$ $\mathrm{N}$ ürnberg, og hoveddel en av materiell og hjel pemidler er blitt tilpasset til bruk i det europeiske programmet. Videre er de foreliggende hjel pemidlene blitt komplettert med materiell om depresjon og suicidal itet som allerede er tilgjengelig $i$ de forskjellige regionene. Resultatet er en katalog med "best practice"-materiale som hele tiden blir oppdatert. 


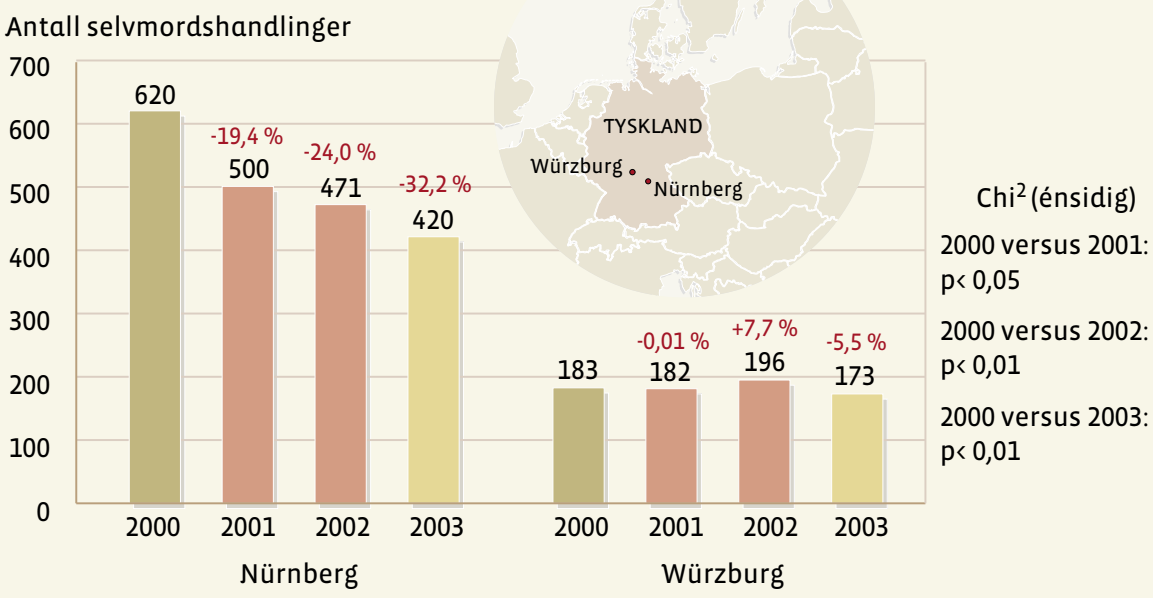

Figur 3 viser signifikant reduksjon i antall selvmordshandlinger i Nürnberg sammenliknet med kontrollregionen Würzburg (2000: basisår, 2001/2002: intervensjon, 2003: oppfølging)

$\mathrm{N}$ år det gjelder evaluering, har EA A Dpartnerne også definert et sett med evalueringsindikatorer for nettverket som omfatter følgende kriterier: antall fullførte selvmord, antall selvmordsforsøk, forskrivningsrate for psykofarmaka (hovedsakelig antidepressiva), måling av effekter av opplæring, samt registrering av endringer i allmennhetens holdninger til depresjon og suicidalitet. Selv om hovedformålet med EA A D er å få iverksatt handlingsplaner, har de fleste partnere samlet inn basisdata fra og med 2004-2005 og foretar videre en systematisk evaluering av effekten av opplæring blant al Imenn praktiserende leger og lokale nøkkel personer, og de samler dessuten forskrivningsdata.

\section{EAAD-nettverket: erfaringer og perspektiver}

Katalogene over "best practice" for felles intervensjonsprogrammer og evaluering har allerede i en viss utstrekning vist hvordan partnerne i EA A D s nettverk klarer å samarbeide. Som følge av ulike strukturer i hel sevesenet og trygdesystemene i landene som deltar, er det ikke mulig å bruke helt ensartede retningslinjer når det fireplans intervensjonsprogrammet skal iverksettes. I stedet setter EA A D s samlede program partnerne i stand til å tilpasse opplegget til sine ulikt utformede helsevesen. På den måten forblir idéen om en flerplans intervensjon den samme i alle landene, men i noen av dem blir den innarbeidet i eksisterende programmer for psykisk helse, mens den i andre utføres som et eget prosjekt. Dessuten er strukturene forskjellige for det enkelte land. $M$ ens noen startet initiativet nedenfra og opp i én region og planlegger å utvide aktivitetene til hele landet på samme måte som "Den tyske alliansen mot depresjon" gjorde, har andre europeiske partnere gått rett løs på en hierarkisk tilnærmingsmåte med et landsomfatten de initiativ, som for eksempel i Island. Til tross for disse individuelle forskjellene deler partnerne sin store interesse for å fortsette arbeidet og i mange tilfeller utvide sine regionale "A Ilianser mot depresjon" til å gjelde hele nasjonen. I for eksempel Sveits, $\varnothing$ sterrike, I talia, Estland og U ngarn er spredningen til lokale regioner allerede i gang. Selv om denne veksten på den ene side er oppmuntrende, representerer den på en annen side en ny utfordring for EA A D-nettverket. H ittil har imidlertid samarbeidet vist at det å følge ett felles intervensjonsprogram og iverksette det på en regionalt individuell måte, er og blir en løfterik fremgangsmåte. Løfterike er også de sterke synergivirkningene av fireplansintervensjonen, noe som skyldes at den på én og samme tid er aktiv på fire plan.

Konklusjonen blir at EA A D kan tjene som et eksempel på hvordan evidensbasert og internasjonalt samfunn sbasert "best practice"-modeller for bedring av omsorgen for deprimerte pasienter og suicidale personer kan implementeres.

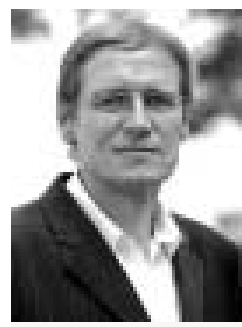

D r. med. U Irich H egerl er styreleder og sjef for Psykiatrisk Institutt ved U niversitetet i Leipzig i Tyskland. $\mathrm{H}$ ans forskningsaktiviteter omfatter implementering og evaluering av selvmordsforebyggen de tiltak, undersøkelse av optimaliserte behandlingsmetoder for lettere og subkliniske depresjonstilstander i primærhelsetjenesten samt forskning med hen blikk på de molekylær-genetiske aspektene ved depressive lidel ser. H egerl er prosjektkoordinator for European A lliance $A$ gain st Depression (EA A D) og dessuten forskningsleder for EA A Ds studie av intervensjon mot depresjon gjennom primærhelsetjenesten, informasjonkampanjer, lokale nøkkel personer, og på høyrisikogruppeplan.

(A rtikkelen er oversatt av Dag Biseth.)

\section{Referanser}

Bertolote, J. M . \& Fleischmann, A . (2005). Suicidal behavior prevention: W H 0 perspectives on research. A m J M ed G enet.C Semin. M ed Genet., 133, 8-12.

Bertolote, J. M., Fleischmann, A ., De Leo, D., \& W asserman, D. (2003). Suicide and mental disorders: do we know enough? Br J Psychiatry, 183, 382-383.

Brent, D. A ., Johnson, B. A ., Perper, J., Connolly, J., Bridge, J., Bartle, S., \& Rather, C. (1994).

Personality disorder, personality traits, impulsive violence, and completed suicide in adolescents. J A m A cad Child A dolesc Psychiatry, 33, 1080-1086.

European Commission. (2005). G reen Paper: Improving the mental health of the population: Towards a strategy on mental health for the European $U$ nion on mental health.

H egerl, U ., A Ithaus, D., Schmidtke, A ., \& Niklewski, G . (2006a). The alliance against depression: 2-year evaluation of a community-based intervention to reduce suicidality. Psychol M ed, 36, 12251233.

H egerl, U ., A Ithaus, D., Schmidtke, A ., \& Niklewski, $G$. (2006b). T he alliance against depression: 2-year evaluation of a community-based intervention to reduce suicidality. Psychol M ed, 36, 1225-1233.

H egerl, U ., W ittmann, M ., A rensman, E., van A udenhove, $C$., Bouleau, J. H., Feltz-C ornelis, $C$., G usmao, R., Kopp, M., Lohr, C., M axwell, M . M eise, U ., M irjanic, M., O skarsson, H., Sola, V. P., Pull, C., Pycha, R., Ricka, R., Tuulari, J., Varnik, A ., \& Pfeiffer-Gerschel, T. (2007). T he 'E uropean A lliance A gainst D epression (EA A D )': A multifaceted, community-based action programme against depression and suicidality. W orld J Biol Psychiatry, 1-8.

H enkel, V., M ergl, R., Kohnen, R., M aier, W. M oller, H . J., \& H egerl, U. (2003). I dentifying depression in primary care: a comparison of different methods in a prospective cohort study. BM J, 326, 200-1.

Lönnqvist, J. \& Koskenvuo, M. (1988). M ortality in depressive disorders; a 3-year prospective followup study in Finland. In: H elgason, T. D. R.

Depressive illness: Prediction of course and outcome (126-130).

Luoma, J. B., M artin, C. E., \& Pearson, J. L. (2002) C ontact with mental health and primary care providers before suicide: a review of the evidence. A m J Psychiatry, 159, 909-916.

M ann, J. J., A pter, A ., Bertolote, J., Beautrais, A ., C urrier, D., H aas, A ., H egerl, U., Lonnqvist, J., M alone, K., M arusic, A ., M ehlum, L., Patton, G., Phillips, M., Rutz, W., Rihmer, Z., Schmidtke, A ., Shaffer, D., Silverman, M ., Takahashi, Y., Varnik, A ., W asserman, D., Yip, P., \& H endin, H. (2005). Suicide prevention strategies: a systematic review. JA M A , 294, 2064-2074.

W asserman, I. M. (1984). Imitation and suicide: A reexamination of the Werther effect. A merican Sociological Review, 49, 427-436.

W orld H ealth Organization. (2003). The World $\mathrm{H}$ ealth Report 2003: Shaping the future. 